\title{
Addressing the Enduring Primary Care Physician Shortage in the United States: The Direct and Indirect Effects of Gender on the Medical Specialty Decision-Making Process
}

Kelly Rhea MacArthur, ${ }^{1}$ Emily Royer, ${ }^{2}$ Daniel N. Hawkins.

\begin{abstract}
Background: There has been an enduring primary care (PC) physician shortage in the United States (U.S.) for decades, which is projected to worsen. With women entering PC at significantly higher rates than men, the aim of this study was to explore various pathways through which gender may affect the medical specialty decision-making process. Methods: Using data from the National Survey of Attitudes and Choices in Medical Education and Training (ACMET) II on a sample of 492 medical residents, this study employed structural equation modeling (SEM) to explore how gender shaped residents preferences for future practice and their perceptions of $\mathrm{PC}$, and how their experiences with faculty affected the medical specialty decision-making process. Results: As expected, women were significantly more likely than men to report choosing PC. This study also found that there were several indirect pathways through which gender affects specialty choice, including through negative perceptions about PC and the time spent with PC faculty in medical school. Conclusion: Given the multiple pathways through which gender affects the medical specialty decision-making process, this study highlights a need for gender-specific interventions when addressing the enduring PC physician shortage in the U.S. Specifically, the results of this study suggest that increasing the time that male medical students spend in $\mathrm{PC}$ through structural changes in medical education might mitigate negative perceptions about $\mathrm{PC}$ and encourage males to enter $P C$ at higher rates. Future research should assess the effectiveness of such gender-specific interventions.
\end{abstract}

Key Words: Medical Education; Primary Health Care; Medical Specialty; Cender Identity; Physician Shortage Area (MeSH Terms).

\section{Introduction}

The Primary Care Physician Shortage in the United States a Gender

Primary Care (PC) physicians, or general practitioners, are doctors on the front-lines of medicine with the responsibility of monitoring patients' overall well-being by providing preventative care, treating most common ailments, and serving as gatekeepers for access to specialists. Family medicine doctors, general internists, general pediatricians, geriatricians, and obstetrician-gynecologists fulfill the vital role of providing the holistic and cost-effective care that characterizes PC specialties. ${ }^{1}$ Despite the well-documented crucial role that PC doctors play for producing better and more equitable health outcomes, generalists only constitute approximately one third of doctors in the United States. ${ }^{2}$ This enduring PC physician shortage dates back at least five decades and is far more severe in America than in many other developed countries.3-5

The extent of and reasons for the PC physician shortage have fluctuated over time, with the percentage of medical students matching to a generalist residency reaching a height of 53.2 percent in 1998 and then steadily declining thereafter. 5 Reasons for the PC shortage have also varied alongside socio-political trends, including: the growing and aging population; the growing income gap between generalists and specialists; the rise of physician assistants and nurse practitioners; socioeconomic deprivation in rural areas; declining income and job satisfaction among PC doctors; and the passage of the Affordable Care Act (ACA) of 2010 that mandated health insurance and increased access to health care for an estimated 34 million Americans.1,5-6 One study estimates that the U.S. will require an additional 52,000 PC doctors by
2025 to keep up with demand, and another study by the American Association of Medical Colleges (AAMC) projects a shortage of approximately 124,000 physicians. ${ }^{1,7}$ Regardless of the future of the ACA, the PC physician shortage is expected to endure and scholars generally agree that by 2025 the demand for PC doctors will far exceed the supply.

The PC physician shortage would be even more dire if not for women's increased rates of entry into PC, which partially compensated for declining rates among men. ${ }^{8}$ Past research has established that gender is perhaps the most powerful predictor of specialty choice, with women entering PC specialties at significantly higher rates compared to men. More than a third of $\mathrm{PC}$ physicians are women, with women comprising the majority of some $P C$ specialties such as family medicine and pediatrics.9 Moreover, approximately half of female physicians are PC doctors compared to about $32 \%$ of male doctors. ${ }^{8-9}$ While this gender segregation is well-documented, the current study contributes to the area by examining how gender affects the ultimate outcome of specialty choice not just directly, but also indirectly through various pathways in the specialty choice decision-making process. ${ }^{8}$ Using the only publicly available, nationally representative data on medical specialty choice, this study seeks to explore how gender might be an effective focal point for the development of strategies to address the increasingly problematic PC physician shortage in the United States.

Factors Affecting Medical Specialty Choice: The Role of Gender Scholars have devoted considerable attention to identifying the factors that affect the process through which medical students choose a specialty. Several meta-analyses indicate that among the factors associated with medical specialty choice are: socio-demographic

\footnotetext{
${ }^{1}$ University of Nebraska Omaha, Omaha, USA.

${ }^{2}$ University of Nebraska Medical Center, College of Medicine, Omaha, USA.
} 
characteristics, such as age and marital status; individuals' values and needs, such as a desire for higher income; individuals' perceptions of a specialty; and the medical school curriculum and institutional culture, such as time spent in PC clerkships and with PC role models/mentors. 6,10 While there are some influences that both men and women cite as important in choosing a specialty, all the aforementioned factors likely vary by gender and affect the medical specialty decision-making process. ${ }^{11}$

Research suggests that there are many reasons why women prefer $P C$ more than men. Unappealing characteristics of $P C-$ both real and perceived-may disproportionately deter men from entering PC. Some of the perceived practice characteristics of $P C$ that may be especially unappealing to men are beliefs that $P C$ is more interpersonally arduous, yet less academically rigorous, and that PC yields lower income and prestige than specialties. Many American residents begin their careers with over $\$ 100,000$ of medical school debt and PC offers less salary than other specialties to compensate for this debt, so it is not surprising that degree of debt is related to PC specialty choice. ${ }^{12-13}$ However, one study shows that even after controlling for debt, women are still more likely to choose $P C$, suggesting that debt is just one factor in the medical specialty decision-making process and does not explain gender differences. PC also tends to offer less flexibility in terms of time. ${ }^{14} \mathrm{As}$ a result, $\mathrm{PC}$ may largely be low among men because it does not allow for a "controllable lifestyle" compared to other sub-specialties. . $^{1-16}$

Conversely, certain specialties such as surgery may be unappealing to many women, due to the overwhelming male predominance that creates male-centric cultures, values, and behaviors, as well as difficulty in finding female mentors. ${ }^{14}$ On average, men tend to prefer medical practices that are characterized by the antithesis of PC, such as high pay, unlimited autonomy, and working with fewer disadvantaged patient populations. Since the decline of $P C$ is inversely associated with the rise of specialties, understanding the PC physician shortage involves examining both why women are drawn to $P C$ and deterred from specialties, as well as why men are deterred from PC and attracted to specialties.?

Individuals enter medical school with certain preferences for their future medical practices and research shows that these preferences are gendered in that women more than men tend to prefer the characteristics that depict PC. ${ }^{14}$ For example, women tend to want to work with disadvantaged patient populations more so than men and PC work allows for more communicative and relationship-focused patient care. ${ }^{14}$ Conversely, males entering medical school report more frequently than women that they desire things like higher income and more autonomy, which accompany specialties more readily than in PC. ${ }^{14}$ Although students have preferences upon entering medical school, research suggests that they often choose a different specialty from the one they declared upon entering medical school. ${ }^{17}$ Thus, it can be inferred that women and men's different experiences in medical school account for a large portion of gender segregation in medical specialties. These gendered experiences may change perceptions about $P C$ and preferences for future practice.

There are several experiences during medical school that could change one's original specialty choice to or from PC. For example, research shows that women are more likely to work with underserved populations in clinics and complete a PC clerkship. ${ }^{18}$ Additionally, the significance of PC physicians serving as positive role models in specialty choice is well-established and this presents a challenge to increasing $P C$ physicians. ${ }^{19}$ As long as negative perceptions of $P C$ prevail, it is unlikely that PC physicians will implicitly or explicitly encourage medical students to enter PC. The time that is spent in PC during clerkships and faculty's encouragement of PC are two other aspects of the medical specialty decision-making process that may also be gendered and affect perceptions about PC.
The Current Study: Conceptual Model for the Effects of Gender on the Medical Specialty Decision Making Process

Gender appears to directly affect not only specialty choice, but also the many aspects of the medical specialty decision-making process. Thus, this study addresses the research question: What are the direct and indirect ways in which gender shapes the medical specialty decisionmaking process? Specifically, how are individual attributes, personal preferences for practicing medicine, perceptions toward PC versus specialties, and experiences during medical school related to each other and in turn affect specialty choice? Based on the literature, the current study tests the conceptual model shown in Figure 1 in which gender will have both direct and indirect effects on PC specialty choice with all of the determinants of specialty choice being related to each other. Specifically, it is hypothesized that there will be a direct effect on $P C$ specialty choice with women reporting significantly higher rates of $P C$ specialty choice than men. It is also hypothesized that women more so than men will 1) desire practice characteristics more specific to $P C$ than other specialties (e.g., wanting to work with underserved populations); 2) have more positive attitudes toward PC; and 3) spend more time with PC physicians who encourage them to enter PC. In turn, the conceptual model predicts that these gendered perceptions, experiences, and preferences account for women's greater likelihood to go into PC. If all these factors are related to each other in the hypothesized manner, then any one of the gendered factors in the medical specialty decision-making process can be targeted for gender specific interventions to increase PC choice for both men and women.

Figure 1. Conceptual Model for Specialty Choice Decision-Making Process

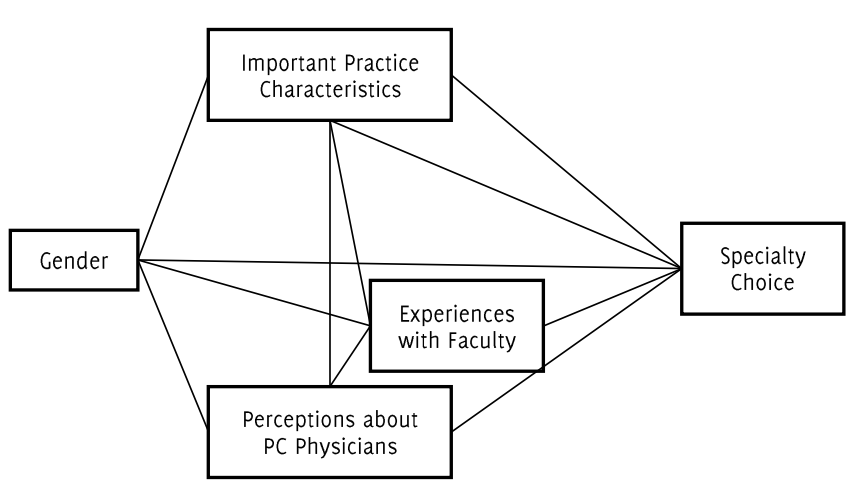

\section{Methods}

\section{Sample}

The data were drawn from the National Survey of Attitudes and Choices in Medical Education and Training (ACMET) II, 1997, which is a nationally representative cross-sectional survey of students, residents, and faculty. ${ }^{20}$ This stratified probability sample includes a variety of variables regarding attitudes toward PC. The current analyses were on a subsample of only the residents, for which there are 492 . Although the data are older, to our knowledge, a nationally-representative data set with a comprehensive set of factors affecting specialty choice and a sufficient sample size of medical residents that is publically available has not been collected more recently. All study procedures were approved by the Institutional Review Board (IRB). The study was approved by Nebraska's Health Science Center Office of Regulatory Affairs Institutional Review Board (IRB) (Approval \#698-16-EX).

\section{Measures}

Dependent Variable: PC Specialty Choice is a dichotomous variable coded $0=$ specialty choice and $1=$ primary care or mixed primary/specialty.

Socio-demographics: All the socio-demographic variables/controls are binary categorical variables coded as gender ( $1=$ female), race/ethnicity 
( $1=$ white), marital status ( $1=$ married or living with partner), and age group ( $1=35$ and older).

Important Characteristics of Future Practice: Respondents were asked "Now I will mention several aspects of practicing medicine in the real world.... As you think about each in the context of your practice choice, I would like you to rate its importance on a scale from o to 10. o means completely unimportant and 10 is as important as an item can be." Residents rated the importance in practicing medicine of: 1) job security, 2) income, 3) autonomy, 4) limiting time spent on the business side of medicine, and 5) devoting a portion of their time to "needy" populations.

Perceptions about PC Physicians: Residents were asked about their perceptions concerning PC physicians' quality of clinical research and clinical teaching compared to specialists', ranging from $1=P C$ physicians are worse than specialists, $2=$ about the same, and $3=P C$ physicians are better than specialists.

Experiences with Faculty: Two items measure residents' experiences with faculty. The first asked whether or not faculty encouraged them to go into PC ( $1=$ strongly toward the specialties to $4=$ strongly toward PC). The second asks about the percentage of time during residency that was spent with PC versus specialist faculty, ranging from $0-100 \%$.

\section{Plan of Analysis}

To address the main research question and the conceptual model shown in Figure 1 regarding the direct and indirect ways in which gender is associated with the specialty choice decision-making process, this study employs Structural Equation Modeling (SEM), using Maximum Likelihood Estimation (MLE). SEM is a superior method for testing hypotheses compared to similar linear techniques, such as multiple regression, because it simultaneously examines relationships between all variables (i.e., the overall model fit), as well as the existence and strength of indirect effects and direct relationships with multiple dependent variables. To assess model fit of the structural model, the Tucker Lewis Index (TLI), Comparative Fit Index (CFI), Root Mean Square Error of Approximation (RMSEA), and Standardized Root Mean Square Residual (SRMR) are reported. All analyses were conducted using the statistical modeling program Mplus 7.31 and uses Maximum Likelihood Estimation (MLE), the standard for SEM models because it produces robust estimates even when assumptions of normality are violated..$^{21,22}$ For all analyses, $p$ values of equal to or less than .05 are considered statistically significant.

\section{Results}

Descriptive Results: Gender Differences in Predictors of Specialty Choice

Table 1 shows descriptive statistics (means, standard deviations, ranges) and results for independent samples t-tests by gender ( $t$ value, significance) for all variables included in this study. The sample of 494 residents was $43.7 \%$ female and about $76 \%$ white. The majority of residents were under the age of 35 and married/living with a partner, with men being significantly more likely than women to be married. Two hundred and five residents $(42.7 \%)$ reported intent to go into PC, with women significantly more likely than men to choose PC.

of the five preferred practice characteristics assessed, both women and men reported that autonomy was the most important, followed by job security. Residents reported that income was the least important out of the 5 'importance' variables. Results of the independent sample ttests indicated that women wanted to limit their time spent on the business side of medicine $(7.54 \pm 7.87, t=-2.29, p<.05)$ and have a practice in which a portion of time is devoted to disadvantaged populations ( $7.12 \pm 2.65, t=-3.23, p<.001)$ significantly more so than men did $(7.13 \pm 2.12$ and $6.48 \pm 2.17$, respectively). There were no gender differences in residents' ratings of importance of job security, autonomy or income
Table 1. Descriptive Statistics for Key Analytic Variables by Gender $(\mathrm{N}=492)$.

\begin{tabular}{|c|c|c|c|c|}
\hline $\begin{array}{l}\text { Dependent } \\
\text { Variable }\end{array}$ & $\begin{array}{c}\text { Women } \\
(n=215)\end{array}$ & $\begin{array}{c}\text { Men } \\
(n=277)\end{array}$ & $\begin{array}{l}t \text {-Test } \\
\text { Value }\end{array}$ & Range \\
\hline $\begin{array}{l}\text { Specialty } \\
\text { Choice }\end{array}$ & $116(55.24)$ & $89(33.21)$ & $-4.91^{\star * *}$ & $\begin{array}{c}1=P C \text { specialty } \\
\text { choice }\end{array}$ \\
\hline \multicolumn{5}{|l|}{$\begin{array}{l}\text { Socio- } \\
\text { demographics }\end{array}$} \\
\hline Race/ethnicity & $153(71.8)$ & $217(78.3)$ & 1.64 & $1=$ white \\
\hline Marital Status & $125(58.4)$ & $203(73.6)$ & $3.52^{* * *}$ & $1=$ married \\
\hline Age & $36(16.7)$ & $38(13.8)$ & -0.90 & $\begin{array}{c}1=35 \text { and } \\
\text { older }\end{array}$ \\
\hline
\end{tabular}

\begin{tabular}{|c|c|c|c|c|}
\hline $\begin{array}{l}\text { Important } \\
\text { Practice } \\
\text { Characteristics }\end{array}$ & $\operatorname{Mean}_{ \pm} \mathrm{SD}$ & Mean $_{ \pm}$SD & & \\
\hline Job Security & $8.47 \pm 1.52$ & $8.49 \pm 1.51$ & 0.20 & $\begin{array}{c}\text { o=completely } \\
\text { unimportant } \\
\text { to } 10=a s \\
\text { important as } \\
\text { an item can }\end{array}$ \\
\hline
\end{tabular}

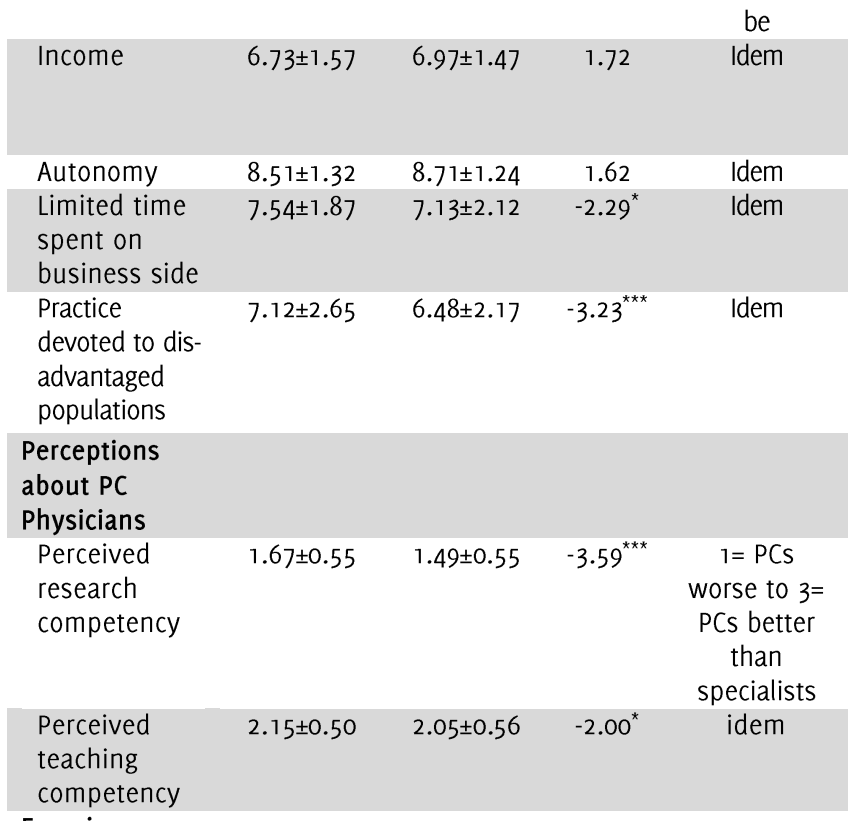

Experiences

with Faculty

\begin{tabular}{|c|c|c|c|c|}
\hline $\begin{array}{l}\text { Faculty } \\
\text { encouraged PC }\end{array}$ & $2.73 \pm 1.07$ & $2.58 \pm 1.04$ & -1.49 & $\begin{array}{l}\text { 1=strongly } \\
\text { toward the } \\
\text { specialties to } \\
\text { 4=strongly } \\
\text { toward PC }\end{array}$ \\
\hline
\end{tabular}

Percentage of $\quad 34.87 \pm 30.46 \quad 22.13 \pm 27.31 \quad-4.81^{\star \star *} \quad 0-100 \%$

time spent

with PC faculty

Legend: ${ }^{*} p<0.05,{ }^{* *} p<0.01,{ }^{* *} p<0.001 . P C$ : Primary care; SD: Standard deviation.

( $t=0.20,1.62$, and 1.72 , respectively). Men had significantly more negative perceptions about PC physicians (research: $1.49 \pm 0.55, \mathrm{t}=-3.59$, $\mathrm{p} \leq 0.001$; teaching: $2.05 \pm 0.56, \mathrm{t}=-2.00, \mathrm{p} \leq 0.05)$ than did women; women perceived PC physicians to be more competent than specialists in both clinical research $(1.67 \pm 0.55)$ and clinical teaching $(2.15 \pm 0.50)$. Women also estimated the time they spent with $P C$ faculty throughout their training to be significantly more $(34.87 \pm 30.46, t=-4.81, p<0.001)$ than 
the time men reported $(22.13 \pm 27.31)$, but there were no gender differences in whether faculty encouraged $P C(t=-1.49)$.

\section{Direct Effects on PC Specialty Choice}

As can be seen in Figure 2, the structural model fit the data well $\left(\mathrm{X}^{2}(\mathrm{~d} f=30)\right.$ $=50.83$, CFI: 0.97, RMSEA: 0.04, SRMR: 0.03). The model fit indices and the $R^{2}$ value (0.569) suggest that the process of choosing PC generally functioned as depicted in Figure 1, with $56.9 \%$ of the variation in specialty choice explained by the tested model. The final model in Figure 2 displayed standardized coefficients for significant relationships only (correlations also not shown). One of the goals of this study was to confirm that gender has a direct effect on medical specialty choice. As expected, women were significantly more likely than men to report that they wanted to go into $P C$ rather than a specialty $(\beta=0.07, p<0.05)$. Without the mediators in the model, this effect of gender on specialty choice would have been substantially stronger $(\beta=0.23, p<0.001)$.

Although not one of the main research questions, since the goal of this study is to identify the factors that affect the medical specialty decision-making process, it is worth noting the direct effects of the predictor variables that affected specialty choice independent of gender. Of the five characteristics of future medical practice on which residents were asked to rate their importance, none of them were directly associated with specialty choice. Residents' perceptions about whether the quality of $\mathrm{PC}$ physicians' clinical teaching compared to specialists' had a direct effect on PC specialty choice. Specifically, those who believed that PC doctors' teaching is 'better' than specialists were more likely to choose to go into PC than a specialty. Respondents' experiences with faculty members during their residencies also had direct associations with choice of specialty. The more that faculty encouraged residents to go into $P C$, the more likely residents reported that they intended to do so $(\beta=0.16, p<0.001)$. Additionally, the more time residents spent with $P C$ faculty, the more likely they were to have chosen $P C(\beta=0.63, p<0.001)$. Thus, in addition to gender, only two of the four types of predictors measured here had direct associations with PC specialty choice.

\section{Indirect Effects on PC Specialty Choice}

As denoted by bolded lines in Figure 2, there were several statistically significant indirect pathways through which gender affected specialty choice (total indirect effects of gender: $\beta=0.16, p<0.001$ ). Gender was indirectly associated with choosing $P C$ through the time spent with $P C$ faculty and perceived research quality. That is, women spent significantly more time with $P C$ faculty, which in turn increased the likelihood of choosing PC. Women also reported significantly more favorable attitudes toward the quality of clinical research that $P C$ physicians do compared to specialists, which had a positive association with time spent with $P C$ faculty, in turn significantly increasing the likelihood of PC specialty choice. The indirect effect of time spent with $P C$ faculty $(\beta=0.01, p<0.000)$, as well as the indirect effect of perceptions toward research quality $(\beta=0.06, p<0.05)$, were both statistically significant. Additionally, even with these partial mediators in the model, the main effect of gender on specialty choice remained (direct effect: $\beta=0.07, p<0.05$ )

Contrary to hypotheses in the conceptual model tested here, there were also indirect effects on specialty choice that did not operate through gender. of the important practice characteristics variables, wanting one's future practice to have a portion of it dedicated to serving disadvantaged populations was indirectly related to PC specialty choice through its positive associations with time spent with PC faculty and perceived research quality. Thus, both experiences with faculty and perceptions about $P C$ doctors explained the effect of disadvantaged populations on specialty choice (total indirect effects: $\beta=0.09, p<0.01$, direct effect: $\beta=0.02, p=0.54$ ).

Residents' perceptions about the quality of PC faculty's clinical research and teaching was partially mediated by the experiences they had with faculty during their internships/residencies (total indirect effects: $\beta=0.12, p<0.001$ ). Perceiving that the quality of $P C$ doctors' clinical research was better than specialists' was indirectly associated with specialty choice through both their positive associations with how strongly faculty encouraged residents to go into $P C$ and the time they spent with PC faculty. The effects of perceptions of PC physicians research was mediated by the experiences that residents had with faculty. While the total indirect effects of perceived teaching quality on specialty choice was statistically significant $(\beta=0.06, p<0.05)$, no single item significantly mediated this relationship.

Figure 2. Standardized Coefficients for the Direct and Indirect Effects of Gender on Specialty Choice Decision-Making Process ( $\mathrm{N}=488)$.

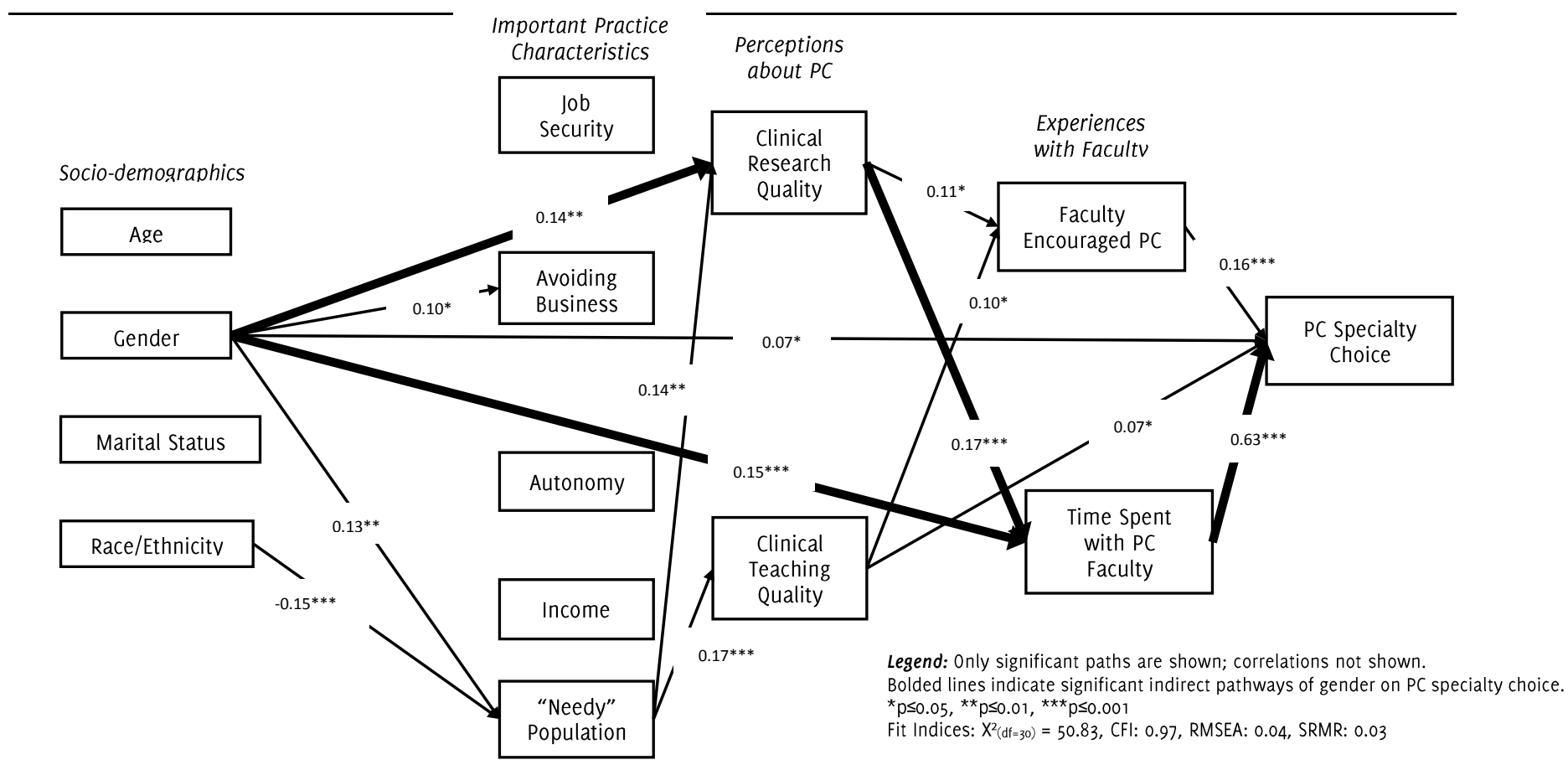




\section{Discussion \\ Summary of Findings}

The purpose of this study was to identify the direct and indirect ways in which gender affects the medical specialty decision-making process, and how those factors are related to each other. As hypothesized and supported by the t-tests, women in this study chose PC at higher rates than men did. Women also placed higher importance than men did on practice characteristics that are perceived to define PC compared to specialties (i.e., more time spent with underserved patients), although there were no gender differences in the desire for autonomy, income, or job security. Women also had more favorable perceptions of $P C$ faculties' competency in research and teaching than men did and, during their residencies, women reported spending a greater proportion of time with PC faculty than men. The structural model also shows that gender was directly associated with PC specialty choice, as well as indirectly related through several paths, including through the time spent with $P C$ faculty and perceived research quality of PC physicians. Taken together, these findings suggest that the medical specialty decision-making process generally functions as hypothesized in the conceptual model depicted in Figure 1, with gender affecting each part of the process.

\section{Breaking the Gendered Cycle}

This study shows that one of the key factors that deters medical students, and in particular men, from entering $P C$ is the negative perception that the quality of research by $P C$ faculty is poor. The specific variable employed in this study likely reflects negative perceptions of PC more broadly, as the devaluation of female dominated fields that leads men to flee is common. ${ }^{17}$ In addition to the gender composition of PC in which more women choose PC than men, the nature of $P C$ practice itself (e.g., the focus on the interpersonal relationship between doctor and patient, the social-psychological aspects of care in PC), is thought of as more feminine, and thus less intellectually demanding than the more technical specialties. ${ }^{14}$ This is an important consideration for graduating medical students, as one study found that the most common reason for choosing their specialty was the perceived intellectual challenge of that field. ${ }^{23}$

Findings showed that men tend to have less favorable attitudes about the quality of PC physicians' clinical research compared to specialists and this is one of the factors that leads them to enter $P C$ at lower rates than women. Therefore, one possible intervention is to attempt to change male's perceptions about PC. However, the increasingly large numbers of women entering medicine, with approximately half of them expected to choose $P C$, may exacerbate the already-established cycle in which PC physicians-both women and men- are more likely to promote and model positive PC to female medical students. To break this cycle and improve men's attitudes toward PC, this study's implications are in alignment with other studies that argue two possible ways to change negative perceptions and increase PC specialty choice: 1) curriculum changes that mandate more time spent in $P C$ and 2) formalized mentorship programs. ${ }^{19,24}$

This study shows that the proportion of time spent with PC versus specialist faculty is an important factor in understanding why more women than men choose PC, as gender was directly and indirectly related to this variable that, in turn, significantly increased the likelihood of choosing PC. Additionally, time spent with faculty was positively associated with perceptions about the quality of $P C$ research, suggesting that negative perceptions about $P C$ are unfounded and do not reflect actual discrepancies in the degree of intellectual rigor of PC compared to specialties. That is, this study suggests that spending more time with $P C$ faculty can change negative perceptions. Increased time spent with PC faculty could be incorporated directly into the medical education curriculum through more required $P C$ clerkships and this would in effect target men to go into $P C$, since as this study shows men report less time spent with $P C$ faculty than do women.
The finding that time spent with $P C$ faculty was related to perceptions about PC and likelihood of choosing PC supports past research showing that more time in $P C$ through increased required clerkships increases entry into PC. ${ }^{25}$ Women, who already have an increased interest in $\mathrm{PC}$ than men, may be attracted to schools that have a greater focus on $P C$ and thus require more PC clerkships. There is some evidence that, when choosing which medical school to attend, women more so than men consider a school's curriculum and they rate PC clerkships as more important than men do. ${ }^{18}$ Especially since women are more likely to complete a primary care clerkship, one possible way to systematically increase time spent in $P C$ would be to make PC clerkships compulsory in more medical schools, which one meta-analysis showed that mandatory clerkships improve attitudes toward PC and increase PC specialty choice, particularly in family medicine. ${ }^{18,22}$ Furthermore, research shows curricula changes over time, such as mandatory $P C$ courses added to the curriculum or entire programs dedicated to $P C$, might produce the most significant increases in rates of $P C$ specialty choice. ${ }^{25}$ Since this study shows that women are already self-selecting themselves into more time spent with $P C$, such changes to the medical education curriculum would in effect be targeting men who would not otherwise choose a PC clerkship or take multiple PC courses- or attend a school that focused on PC in the first place.

Some of the gender difference in the variable employed here about "contact time" with PC faculty may be attributable to informal time spent with PC faculty because women who are already more interested in PC specialties may be more likely to seek out, and subsequently form relationships with, $P C$ faculty. Since ethical considerations would preclude the development of gender-specific curriculum requirements, a more feasible point of intervention would be to focus on potential PC faculty role-models. Prior research has established the importance of mentors, in a variety of role-modeling capacities, in the medical specialty decision-making process, although there is some evidence that early role models are more influential in choosing PC for men, while personal factors such as family responsibilities are more influential for women. ${ }^{19,26-29}$ Since role models can also be a negative influence on PC specialty choice, it is important to more formally institutionalize mentorship programs designed specifically to increase PC specialty choice. ${ }^{6}$

Since there is no conclusive evidence that women $P C$ faculty are more likely to suggest $P C$ than are men PC faculty, to reverse the gendered cycle, more $P C$ faculty need to explicitly encourage male medical students to enter PC. While most women and men PC faculty likely naturally encourage students to enter $P C$ already, this study suggests that formalized mentorship programs, such as those in which students are assigned a faculty membership and participate in, for example, shadowing. Faculty could volunteer to participate in a mentorship program (and receive financial incentives to do so) to focus on identifying and encouraging male medical students into PC over the course of students' medical education. The findings of this study suggest that long-term curriculum changes and mentorship programs might be especially efficacious in recruiting men into PC and thus addressing the $P C$ physician shortage.

\section{Conclusion}

\section{Limitations}

This study has several limitations, one of which is that this study could not determine causal order and so we cannot determine whether spending time with PC faculty differentially affects women's and men's specialty choices or if there is a selection effect in which women spend more time with $P C$ faculty because they are more interested in $P C$ in the first place. Similarly, we cannot establish the causal order between perceptions about PC physicians and time spent with PC faculty. However, given the multiple pathways to $P C$ specialty choice and the 
correlations among the various factors, this study suggests that changing one of the predictor variables is likely to affect the others.

Another limitation is that this study does not include several important factors known to be related to medical specialty choice and that differ by gender, such as a desire for specialties that allow for a "controllable lifestyle," meaning those specialties that allow for greater balance between domestic and work duties. ${ }^{11,27}$ While it was beyond the scope and intent of this study to examine all possible factors in the medical specialty decision-making process, this study nonetheless demonstrates that gender affects this process through a multitude of pathways of which any of them can be targeted to encourage either or both women and/or men to enter PC and decrease the enduring PC physician shortage in the U.S.

The most notable limitation of this study is that the data were collected in 1997 and there have been major changes in the American health care system since then that have conceivably affected the ways in which gender affects the medical specialty decision-making process. However, medical education tends to be a self-reproducing institution that produces stability over time in the gendered medical specialty decisionmaking process. ${ }^{17}$ Furthermore, many of the gendered patterns in specialty choice are a reflection of gendered socialization in the larger society, which has likewise not drastically changed since the $1990 .^{18}$ Therefore, there seems to be a "cycle" that has been largely unaffected throughout time of more women choosing $\mathrm{PC}$ than men perpetuating the perceived culture of $P C$ as feminine and less academically rigorous and leading to more women- and less men- choosing PC.

In this paper, we argue that the importance of this study's focus on identifying gender differences in specialty choice lies within its implications for addressing the enduring primary care physician shortage in the U.S. PC specialty choice has been steadily decreasing since the time this data were collected, which was at the peak of PC specialty choice among medical students in the mid-1990s. ${ }^{11}$ Thus, the older data employed here likely underestimates the extent of the $P C$ physician shortage. Additionally, PC specialty choice among men continues to decline, while women have been relatively consistently about 1.5 times more likely to choose a PC specialty than men through the mid-2000s and now into the current era.8,30 The increasing absolute number of women entering medical school has kept the primary care physician shortage from being even more problematic than it currently is. However, the likelihood of this pattern continuing is precarious.

As primary care becomes increasingly female-dominated, it is also likely that the salary gap-as well as the level of prestige-between PC and other specialties will continue to grow, as it has in other occupations with a growing percentage of women. 8,17 In turn, if women begin to gravitate even more to non-PC specialties, where the gender pay gap is smaller and not rife with negative perceptions due in part to its feminization, it will exacerbate the PC physician shortage. $8,14,17$ In spite of the data collected around the historical height of PC, the gender differences identified in this study are likely to have remained stable and thus the curriculum changes of required PC clerkships/electives and formal mentorship programs are still relevant, and arguably increasingly applicable, in order to address gender differences in specialty choice.

Future research should continue to examine the conceptual frameworks and specific variables that affect medical specialty choice and how these factors vary by gender. In particular, researchers should seek to examine whether and how increased time spent in $P C$ through structural changes in medical school (i.e., mandatory PC clerkships/courses and formalized mentorship programs) improve men's perceptions about PC. Furthermore, given that there are several pathways through which gender affects $P C$ specialty choice, targeting any one of the factors in the conceptual model tested here is likely to affect the entire medical specialty decision-making process. Thus, this study contributes to the literature on primary care specialty choice by offering a conceptual model with gender as the focal point and one that points to structural changes in medical education as the solution as opposed to the gendered preferences and styles that women and men bring with them into medical school. Specifically, this study suggests that changing men's perceptions of $P C$ by increasing their time spent with PC faculty in medical school has the most potential to positively address the enduring PC physician shortage in the U.S., which is increasingly critical in order to create a sustainable and cost-effective health care system that promotes a healthy population. 


\section{References}

1. Petterson SM, Liaw WR, Phillips RL, Rabin DL, Meyers DS, Bazemore AW. Projecting US primary care physician workforce needs: 2010-2025. Ann Family Med. 2012 Nov $1 ; 10(6): 503-9$

2. Agency for Healthcare Research and Quality. Fact Sheets: The Number of Practicing Primary Care Physicians in the United States. Available at: http://www.ahra.gov/research/findings/factsheets/primary/pcwork1/index.html.

3. Association of American Medical Colleges. Workforce Studies. Available at: http://www.aamc.org/workforce.

4. Macinko J, Starfield B, Shi L. The contribution of primary care systems to health outcomes within Organization for Economic Cooperation and Development (OECD) countries, 1970-1998. Health Serv Res. 2003 Jun;38(3):831-65.

5. Newton DA, Grayson MS. Trends in career choice by US medical school graduates. Jama. 2003 Sep 3;290(9):1179-82.

6. Senf JH, Campos-Outcalt D, Kutob R. Factors related to the choice of family medicine: a reassessment and literature review. J Am Board Fam Pract. 2003 Nov-Dec;16(6):502-12.

7. Dill MJ, Salsberg ES. The complexities of physician supply and demand: projections through 2025. Association of American Medical Colleges; 2008.

8. Tu HT, O'Malley AS. Exodus of male physicians from primary care drives shift to specialty practice. Tracking Report. 2007 Jun;17:1-6.

9. Brotherton SE, Rockey PH, Etzel SI. US graduate medical education, 2004-2005: trends in primary care specialties. Jama. 2005 Sep 7;294(9):1075-82.

10. Bland CJ, Meurer LN, Maldonado G. Determinants of primary care specialty choice: a non-statistical meta-analysis of the literature. $1995 \mathrm{Jul}$ 1:70(7):620-41.

11. Lambert EM, Holmboe ES. The relationship between specialty choice and gender of US medical students, 1990-2003. Acad Med. 2005 Sep 1;80(9):797-802.

12. Woodworth PA, Chang FC, Helmer SD. Debt and other influences on career choices among surgical and primary care residents in a community-based hospital system. The Am Surg. 2000 Dec 1;180(6):570-6.

13. Rosenblatt RA, Andrilla CH. The impact of US medical students' debt on their choice of primary care careers: an analysis of data from the 2002 medical school graduation questionnaire. Acad Med. $2005 \operatorname{Sep}$ 1;80(9):815-9.

14. Hoff T. Practice under pressure: Primary care physicians and their medicine in the twenty-first century. Rutgers University Press; 2009 Sep 11.

15. Dorsey ER, Jarjoura D, Rutecki CW. Influence of controllable lifestyle on recent trends in specialty choice by US medical students. Jama. 2003 Sep 3;290(9):1173-8.

16. Lind DS, Cendan JC. Two decades of student career choice at the University of Florida: increasingly a lifestyle decision. Am Surg. 2003;69(1):53.
17. Boulis AK, Jacobs JA. The changing face of medicine: women doctors and the evolution of health care in America. Cornell University Press; 2008 0ct 9.

18. Bickel J, Ruffin A. Cender-associated differences in matriculating and graduating medical students. Acad Med. 1995 Jun; 70(6):552-9.

19. Campos-Outcalt D, Senf J, Watkins AJ, Bastacky S. The effects of medical school curricula, faculty role models, and biomedical research support on choice of generalist physician careers: a review and quality assessment of the literature. Acad Med. 1995 Jul; $70(7): 611-9$.

20. Block, Susan D. National Survey of Attitudes and Choices in Medical Education and Training (ACMET) II, 1997 [Computer file]. ICPSR version. Boston, MA: University of Massachusetts-Boston Center for Survey Research [producer], 1997. Ann Arbor, MI: Interuniversity Consortium for Political and Social Research [distributor], 2002

21. Muthen LK. Mplus: Statistical Analysis with Latent Variables (Version 4.21) Computer software.

22. Kline RB. Principles and practice of structural equation modeling. Guilford publications; 2015 Nov 3.

23. Wendel TM, Godellas CV, Prinz RA. Are there gender differences in choosing a surgical career?. Surgery. 2003 Oct 1;134(4):591-6.

24. Conzales A0, Westfall J, Barley GE. Promoting medical student involvement in primary care research. Fam Med. 1998 Feb;30(2):113-6.

25. Pfarrwaller E, Sommer J, Chung C, Maisonneuve H, Nendaz M, Perron NJ, Haller DM. Impact of interventions to increase the proportion of medical students choosing a primary care career: a systematic review. J Gen Intern Med. 2015 Sep 1;30(9):1349-58.

26. Doucet $H$, Shah MK, Cummings TL, Kahn MJ. Comparison of internal medicine, pediatric, and medicine/pediatrics applicants and factors influencing career choices. South Med J. 1999 Mar;92(3):296-9.

27. Harris MC, Marx J, Gallagher PR, Ludwig S. Ceneral vs subspecialty pediatrics: factors leading to residents' career decisions over a 12-year period. Arch Pediatr Adolesc Med. 2005 Mar 1;159(3):212-6.

28. Osborn EH. Factors influencing students' choices of primary care or other specialties. Acad Med. 1993 Jul;68(7):572-4.

29. Xu G, Rattner SL, Veloski JJ, Hojat M, Fields SK, Barzansky B. A national study of the factors influencing men and women physicians' choices of primary care specialties. Acad Med. 1995 May;70(5):398-404.

30. Association of American Medical Colleges (AAMC). 2017. Number of Active Residents, by Type of Medical School, GME Specialty, and Sex. 2016-2017 Active Residents. Available at: https://www.aamc.org/data/493922/report-on-residents-2018bztable.html.

\section{Acknowledgments}

None

\section{Conflict of Interest Statement it Funding}

The Authors have no funding, financial relationships or conflicts of interest to disclose.

\section{Author Contributions}

Conceptualization: KRM, EGR, DHN. Methodology: KRM. Validation: EGR. Formal Analysis: KRM. Investigation: EGR. Data Curation: KRM. Resources: KRM. Writing - Original Draft: KRM, EGR. Writing - Review \& Editing: KRM, EGR, DHN; and Supervision: DHN.

Cite as:

MacArthur KR, Royer E, Hawkins D. Addressing the Enduring Primary Care Physician Shortage in The United States. Int J Med Students. 2018;6(3):91-7. This work is licensed under a Creative Commons Attribution 4.0 International License 